\title{
Exploring the Pregnant Guinea Pig as a Model for Group B Streptococcus Intrauterine Infection
}

\author{
Maria I Harrell ${ }^{1}$, Kellie Burnside ${ }^{1}$, Christopher Whidbey ${ }^{1,2}$, Jay Vornhagen ${ }^{1,2}$, Kristina M Adams Waldorf ${ }^{2,3}$ and Lakshmi Rajagopal $^{1,2^{*}}$ \\ ${ }^{1}$ Department of Pediatrics, University of Washington and Seattle Children's Research Institute, Seattle, Washington, United States of America \\ ${ }^{2}$ Department of Global Health, University of Washington, Seattle, Washington, United States of America \\ ${ }^{3}$ Department of Obstetrics and Gynecology, School of Medicine, University of Washington, Seattle, Washington, United States of America
}

"Corresponding author: Rajagopal L, Department of Pediatrics, University of Washington and Seattle Children's Research Institute, Seattle, Washington, United States of America, Tel: 206-884-7336; E-mail: lakshmi.rajagopal@seattlechildrens.org

Received date: July 10, 2017; Accepted date: July 20, 2017; Published date: July 27, 2017

Copyright: $\odot 2017$ Harrell MI, et al. This is an open-access article distributed under the terms of the Creative Commons Attribution License; which permits unrestricted use; distribution; and reproduction in any medium; provided the original author and source are credited.

\begin{abstract}
Infection of the amniotic cavity remains a major cause of preterm birth, stillbirth, fetal injury and early onset, fulminant infections in newborns. Currently, there are no effective therapies to prevent in utero infection and consequent co-morbidities. This is in part due to the lack of feasible and appropriate animal models to understand mechanisms that lead to in utero infections. Use of mouse and rat models do not fully recapitulate human pregnancy, while pregnant nonhuman primate models are limited by ethical considerations, technical constraints, and cost. Given these limitations, the guinea pig is an attractive animal model for studying pregnancy infections, particularly as the placental structure is quite similar to the human placenta. Here, we describe our studies that explored the pregnant guinea pig as a model to study in utero Group B Streptococci (GBS) infections. We observed that intrauterine inoculation of wild type GBS in pregnant guinea pigs resulted in bacterial invasion and dissemination to the placenta, amniotic fluid and fetal organs. Also, hyperhemolytic GBS such as those lacking the hemolysin repressor CovR/S showed increased dissemination into the amniotic fluid and fetal organs such as the fetal lung and brain. These results are similar to those observed in mouse and non-human primate models of in utero infection, and support use of the guinea pig as a model for studying GBS infections in pregnancy.
\end{abstract}

Keywords: Pregnant guinea pig; Streptococcus; Intrauterine; Infection

\section{Introduction}

Group B Streptococci are $\beta$-hemolytic gram-positive bacteria that commonly reside in the lower gastrointestinal tract of healthy women. However, an ascending infection of GBS from the vagina into the uterus during pregnancy increases the risk of preterm birth, stillbirth and early onset newborn infections. Despite observations that link GBS colonization of the lower genital tract to chorioamnionitis, rupture of membranes and transmission to the fetus, the mechanisms that promote ascending infection are not completely understood [1-3]. How changes in host pathogen interactions influence ascending infection are not well described [3]. Additionally, environmental factors that promote ascending infection of GBS are not completely elucidated. Furthermore, the lack of appropriate animal models contributes to the knowledge gap on infections that occur during pregnancy. This is because no animal model fully recapitulates human pregnancy. Also, single species animal models are limited in their ability to fully reproduce human physiology. In order to successfully replicate human disease, especially those that occur during complex physiological processes such as pregnancy, multiple experimental models are necessary. Recently, much work has been done to develop the pregnant mouse and non-human primate models of GBS infection during pregnancy [4-11]. Although pregnancy in nonhuman primates more closely resembles human pregnancy, their application is limited due to constraints on ethical use, requirement of a large team of specialized experts and costs [9-12]. While the mouse is commonly used to study infections during pregnancy, limitations include key differences with human pregnancy in the mechanism of parturition, uterine and placental structure, gestational length and sensitivity to common perinatal pathogens [9].

The pregnant guinea pig (Cavia porcellus) is a closer model of human pregnancy based on similarities in progesterone levels across gestation and at the time of parturition, placental structure (i.e., hemomonochorial), deep trophoblast invasion and remodelling of the maternal spiral arteries, sensitivity to pathogens, prolonged gestation ( $\sim 67$ days in guinea pig versus $\sim 21$ days in mouse) and advanced maturity of the neonate [13-18]. Pregnant guinea pigs are considered to be a highly relevant non-primate animal model for studies of chronic placental hypoxia [18], fetal growth restriction and multiple bacterial (e.g. L. monocytogenes, E. coli and C. trachomatis) and viral infections [19-25] (e.g. Zika virus [26], cytomegalovirus [27]). The addition of the guinea pig model to the mouse and non-human primate models will increase the relevance of factors that enable GBS establish infections during pregnancy.

To confirm that the pregnant guinea pig would be useful for studies on GBS infection during pregnancy, we adapted an established mouse model of intrauterine infection [28-30] to the guinea pig. Pregnant Hartley guinea pigs at $\sim 39-40$ days gestation (term $\sim 59-72$ days) were obtained from Elm Hill Labs, MA, USA. To expose the uterine horns, a midline laparotomy was performed on pregnant guinea pigs at 45 days gestation under isoflurane anaesthesia, as described for the mouse model [28-30]. The guinea pig uterus is bicornuate and may contain between 1-6 fetuses during pregnancy. Two membranes known as the yolk sac placenta and amnion enclose each fetus (Figure 1). The yolk sac placenta is the anatomical and functional equivalent of the human chorion, and the guinea pig amnion has structural similarity to the 
human amnion [16-31,32]. As cervical or vaginal inoculations may result in inconsistent pregnancy outcomes, GBS was inoculated directly into the uterus inferior to the lowest pup to allow bacterial spread into both uterine horns. Either saline $(n=1)$ or $10^{7}$ colony forming units (CFU) of a wild-type (WT) GBS strain (serotype III, $\mathrm{COH}-1 ; n=2)$ or an isogenic hyper-virulent, and hyper-hemolytic GBS strain $(\mathrm{GBS} \Delta \operatorname{covR}, n=2)$ was injected between the uterine horns, with care not enter a fetal sac or placenta (Figure 1). The uterus was then returned to the abdomen, which was then closed using absorbable suture. The animals recovered within $10 \mathrm{~min}$ of the procedure and were observed for signs of distress or morbidity (piloerection, vaginal bleeding, and preterm delivery). To confirm GBS dissemination into fetal tissues, we terminated the experiment at $\sim 8 \mathrm{hrs}$ post-infection when the animals did not exhibit signs of distress or evidence of preterm labor. Guinea pigs were euthanized by humane means and a necropsy was performed. Amniotic fluid, and fetal organs, such as the lung and brain were harvested from each fetus individually. Bacterial $\mathrm{CFU}$ were enumerated in various tissues.

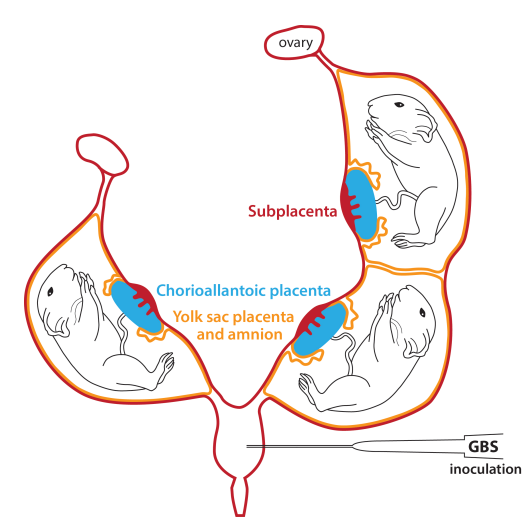

Figure 1: Schematic representation of the bicornuate guinea pig uterus with fetal sacs in each horn.

The results shown in Figure 2 indicate that WT GBS are able to invade placental membranes, survive in amniotic fluid and penetrate fetal organs such as the lung, and brain in the pregnant guinea pig model. The hypervirulent GBS strain (GBS $\Delta \operatorname{covR}$ lacking the hemolysin repressor CovR/S) used in this study has previously been associated with increased placental invasion and preterm births $[7,30,33]$. Consistent with these observations, GBS $\Delta \operatorname{cov} R$ exhibited increased invasion/dissemination when compared to the WT strain (Figure 2). Of note, we did not recover bacteria from the saline control animal.

Our studies are the first to demonstrate that intrauterine inoculation outside the fetal sacs results in GBS invasion of fetal lung and brain in the pregnant guinea pig model. Further studies are needed for evaluation of the guinea pig as an appropriate model for studies of GBS infection-associated preterm birth and stillbirth.

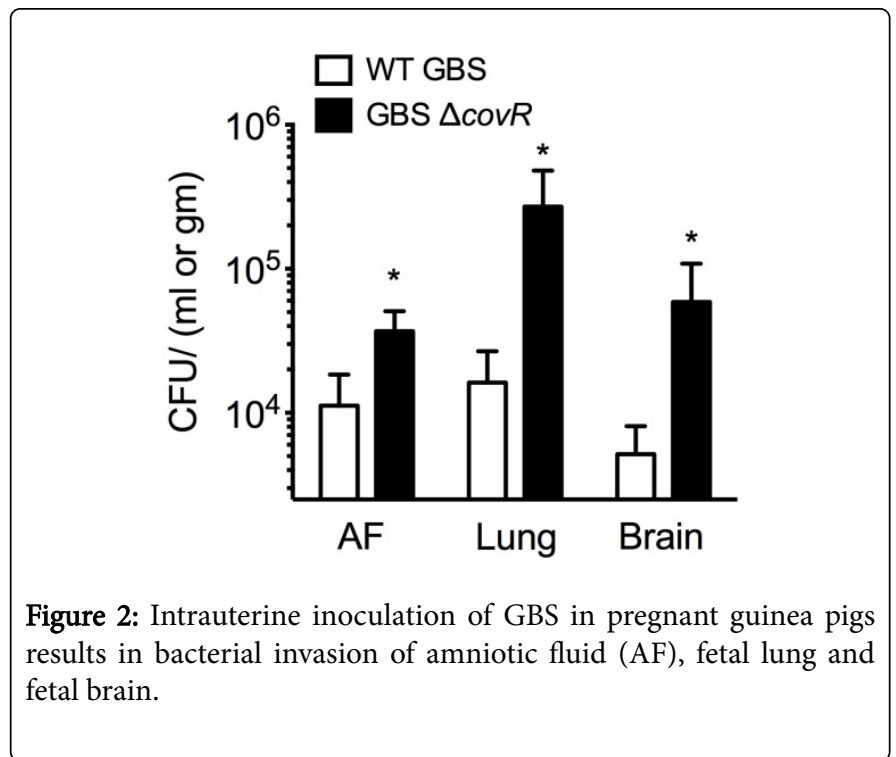

\section{Discussion}

Although the pregnant guinea pig is more similar to human when compared to murine models, disadvantages of the guinea pig include greater cost, genetic intractability and limited reagents (e.g. guinea pigspecific antibodies) when compared to mice; however, new guinea pigspecific reagents are regularly being developed [24]. Nevertheless, our initial observations with the pregnant guinea pig links intrauterine inoculation of GBS to bacterial invasion of placenta, amniotic fluid and fetal organs, which mirror what is observed in the pregnant mouse model and the nonhuman primate model of in utero GBS infection $[7,30]$. These results confirm the feasibility of this animal model for additional studies of GBS infections.

While intrapartum prophylactic antibiotic administration during labor and delivery has proven to be effective in reducing the burden of neonatal GBS disease, it has not halted disease incidence. Additionally, ascending GBS infection is highly associated with stillbirth and preterm birth. A significant portion of these infections are attributable to in utero infections early in pregnancy, yet little is known about how these infections occur. Multiple studies have described the role of the GBS hemolytic pigment in ascending and in utero infection $[5,7,30]$, and our data here corroborate these findings in the pregnant guinea pig model. Moreover, GBS that overexpress the hemolytic pigment have been isolated from women undergoing preterm labor and in other cases of severe infection [33-36]. Establishment of the role of a virulence factor in bacterial disease pathogenesis is necessary for identification and testing of therapeutics and vaccines. Prevention of infections during pregnancy requires testing in many animal models prior to clinical trials due to differences in aspects of pregnancy in the various animal models and sensitivity of the developing fetus. Our studies show that pregnant guinea pig can serve as an appropriate model for studies on GBS infections during pregnancy.

All animal experiments were approved by the Seattle Children's Research Institutional Animal Care and Use Committee (protocol \#13907) and performed in strict accordance with the recommendations in the Guide for the Care and Use of Laboratory Animals of the National Institutes of Health ( $8^{\text {th }}$ Edition). All surgery 
was performed with appropriate anaesthesia and analgesia, and every effort was made to minimize suffering.

Pregnant guinea pigs at $\sim 39-40$ days gestation (term 59-72 days) were obtained from Elm Hill Labs, MA, USA. Briefly, on 45 days gestation, dams were anesthetized using isoflurane (3-4\%) via nose cone and maintained under anaesthesia during the duration of the procedure. Sterile surgical techniques were used. Subcutaneous injection of buprenorphine $(0.025 \mathrm{mg} / \mathrm{kg}$, (Webster Veterinary Supply) was administered pre-operatively.

The surgical site at the caudal abdomen was shaved and prepared using triple alternation of betadine scrub /alcohol scrub around surgical site. Subsequently, a ventral midline laparotomy was performed to expose uterine horns via midline incisions into the caudal abdominal skin and peritoneum as described for mice [29]. Approximately, $10^{7} \mathrm{CFU}(100 \mu \mathrm{L})$ of GBS was injected between the uterine horns inferior to the lowest pup. After inoculation, sterile saline was applied to the exposed uterus, and the uterus was returned to the abdomen. Subsequent to GBS inoculation, the abdomen was closed in 3 layers (muscle, subcutaneous using absorbable suture (Vicryl 3-0, Medline Industries) and intradermal and/or skin with absorbable suture and skin glue as needed (Dermabond skin adhesive, Medline industries). Replacement fluids $(10 \mathrm{ml} / \mathrm{kg} / \mathrm{hr}$ sterile $0.9 \%$ $\mathrm{NaCl}$ or lactated ringers solution) were given subcutaneously at the conclusion of surgery. The animals were placed in a recovery cage on a heating pad and observed until ambulatory and then every 2 hrs postsurgery till experimental end at $8 \mathrm{hrs}$, at which point they did not exhibit preterm birth (vaginal bleeding and pup in cage) or morbidity symptoms (ruffling of fur, not eating/drinking, lack of spontaneous movement, fatigue, labored breathing, lethargy or significant weight loss, $>10 \%$ ). Animals were euthanized at 8 hours post infection using anesthesia first with isoflurane (5\% in an induction chamber) and then, following no response to toe pinch, $100 \mathrm{mg} / \mathrm{kg}$ of pentobarbital (Webster Veterinary Supply) was injected intraperitoneally or intracardiac. Fetuses were euthanized by decapitation and fetal tissues were collected and homogenized for enumeration of bacterial CFU by serial dilution and plating using methods described [7].

\section{Acknowledgement}

We thank Dr. Ida Washington for assistance with the Guinea Pig surgeries, Dr. M. Elovitz and Dr. M Chan for expert advice, and Ms. Jan Hamanishi for graphical assistance.

Funding from the National Institutes of Health, Grants R01AI100989 to L.R and K.M.A.W and R21 AI109222 to L.R supported this work.

C.W and J.V were supported by the NIH training grant (T32 AI07509, PI: Lee Ann Campbell). The content is solely the responsibility of the authors and does not necessarily represent the official views of the National Institutes of Health.

\section{Author Contributions}

M.I H., K. B., C.W., J. V., K.M.A.W and L.R performed the experiments, analysed the results and wrote the paper.

\section{Competing Financial Interests}

The authors declare no competing financial interests.

\section{References}

1. Novak RW, Platt MS (1985) Significance of placental findings in earlyonset group B streptococcal neonatal sepsis. Clinical Pediatrics 24: 256-258

2. Boggess KA, Watts DH, Hillier SL, Krohn MA, Benedetti TJ, et al. (1996) Bacteremia shortly after placental separation during cesarean delivery. Obstet Gynecol 87: 779-784.

3. Vornhagen J, Adams Waldorf KM, Rajagopal L (2017) Perinatal Group B streptococcal infections: Virulence factors, immunity, and prevention strategies. Trends Microbiol S0966-842X: 30127-30130.

4. Vornhagen J, Quach P, Boldenow E, Merillat S, Whidbey C, et al. (2016) Bacterial hyaluronidase promotes ascending GBS infection and preterm birth. MBio 7: e00781-16.

5. Randis TM, Gelber SE, Hooven TA, Abellar RG, Akabas LH, et al. (2014) Group B Streptococcus beta-hemolysin/cytolysin breaches maternal-fetal barriers to cause preterm birth and intrauterine fetal demise in vivo. J Infect Dis 210: 265-273.

6. Kothary V, Doster RS, Rogers LM, Kirk LA, Boyd KL, et al. (2017) Group $B$ streptococcus induces neutrophil recruitment to gestational tissues and elaboration of extracellular traps and nutritional immunity. Front Cell Infect Microbiol 7: 19.

7. Boldenow E, Gendrin C, Ngo L, Bierle C, Vornhagen J, et al. (2016) Group B streptococcus circumvents neutrophils and neutrophil extracellular traps during amniotic cavity invasion and preterm labor. Sci Immunol 1: eaah4576.

8. Adams Waldorf KM, Gravett MG, McAdams RM, Paolella LJ, Gough GM, et al. (2011) Choriodecidual group B streptococcal inoculation induces fetal lung injury without intra-amniotic infection and preterm labor in Macaca nemestrina. PLoS One 6: e28972.

9. Adams Waldorf KM, Rubens CE, Gravett MG (2011) Use of nonhuman primate models to investigate mechanisms of infection-associated preterm birth. BJOG 118: 136-144.

10. McAdams RM, Vanderhoeven J, Beyer RP, Bammler TK, Farin FM, et al. (2012) Choriodecidual infection downregulates angiogenesis and morphogenesis pathways in fetal lungs from macaca nemestrina. PLoS ONE 7: e46863.

11. Grigsby PL, Novy MJ, Waldorf KM, Sadowsky DW, Gravett MG (2010) Choriodecidual inflammation: a harbinger of the preterm labor syndrome. Reprod Sci 17: 85-94.

12. Gravett MG, Witkin SS, Haluska GJ, Edwards JL, Cook MJ, et al. (1994) An experimental model for intraamniotic infection and preterm labor in rhesus monkeys. Am J Obstet Gynecol 171: 1660-1667.

13. Grigsby PL (2016) Animal models to study placental development and function throughout normal and dysfunctional human pregnancy. Semin Reprod Med 34: 11-16.

14. Mitchell BF, Taggart MJ (2009) Are animal models relevant to key aspects of human parturition? Am J Physiol Regul Integr Comp Physiol 297: R525-545.

15. Mess A (2007) The guinea pig placenta: Model of placental growth dynamics. Placenta 28: 812-815.

16. Kaufmann P (2004) Guinea pig cavia porcellus. Comparative Placentation.

17. Benirschke K, Kaufmann P, Baergen R (2006) Pathology of the human placenta. Springer Science+ Business Media Inc, NY, USA.

18. Thompson LP, Pence L, Pinkas G, Song H, Telugu BP (2016) Placental hypoxia during early pregnancy causes maternal hypertension and placental insufficiency in the hypoxic guinea pig model. Biol Reprod 95: 128.

19. Bakardjiev AI, Stacy BA, Fisher SJ, Portnoy DA (2004) Listeriosis in the pregnant guinea pig: A model of vertical transmission. Infect Immun 72: $489-497$

20. de Jonge MI, Keizer SA, El Moussaoui HM, van Dorsten L, Azzawi R, et al. (2011) A novel guinea pig model of Chlamydia trachomatis genital tract infection. Vaccine 29: 5994-6001. 
Citation: Harrell MI, Burnside K, Whidbey C, Vornhagen J, Adams Waldorf KM, et al. (2017) Exploring the Pregnant Guinea Pig as a Model for Group B Streptococcus Intrauterine Infection. J Infect Dis Med 2: 109. doi:10.4172/2576-1420.1000109

Page 4 of 4

21. Patrick LA, Gaudet LM, Farley AE, Rossiter JP, Tomalty LL, et al. (2004) Development of a guinea pig model of chorioamnionitis and fetal brain injury. Am J Obstet Gynecol 191: 1205-1211.

22. Wang B, Navath RS, Menjoge AR, Balakrishnan B, Bellair R, et al. (2010) Inhibition of bacterial growth and intramniotic infection in a guinea pig model of chorioamnionitis using PAMAM dendrimers. Int J Pharm 395: 298-308.

23. Rank RG, Bowlin AK, Reed RL, Darville T (2003) Characterization of chlamydial genital infection resulting from sexual transmission from male to female guinea pigs and determination of infectious dose. Infect Immun 71: 6148-6154.

24. Padilla-Carlin DJ, McMurray DN, Hickey AJ (2008) The guinea pig as a model of infectious diseases. Comp Med 58: 324-340.

25. Frazer LC, Darville T, Chandra-Kuntal K, Andrews CW, Zurenski M, et al. (2012) Plasmid cured chlamydia caviae activates TLR2-dependent signaling and retains virulence in the guinea pig model of genital tract infection. PLoS ONE 7: e30747.

26. Kumar M, Krause KK, Azouz F, Nakano E, Nerurkar VR (2017) A guinea pig model of Zika virus infection. Virol J 14: 75.

27. Kern ER (2006) Pivotal role of animal models in the development of new therapies for cytomegalovirus infections. Antiviral Res 71: 164-171.

28. Elovitz MA, Wang Z, Chien EK, Rychlik DF, Phillippe M (2003) A new model for inflammation-induced preterm birth: The role of plateletactivating factor and Toll-like receptor-4. Am J Pathol 163: 2103-2111.
29. Hirsch E, Saotome I, Hirsh D (1995) A model of intrauterine infection and preterm delivery in mice. Am J Obstet Gynecol 172: 1598-1603.

30. Whidbey C, Vornhagen J, Gendrin C, Boldenow E, Samson JM, et al. (2015) A streptococcal lipid toxin induces membrane permeabilization and pyroptosis leading to fetal injury. EMBO Mol Med 7: 488-505.

31. Goldhawk DE, Carter D, Hobkirk R (1996) Microscopic and biochemical analysis of the viability and permeability of guinea pig amnion and chorion leave in vitro. J Exp Zool 275: 383-397.

32. Welsh T, Mitchell CM, Walters WA, Mesiano S, Zakar T (2005) Prostaglandin $\mathrm{H} 2$ synthase-1 and -2 expression in guinea pig gestational tissues during late pregnancy and parturition. J Physiol 569: 903-912.

33. Whidbey C, Harrell MI, Burnside K, Ngo L, Becraft AK, et al. (2013) A hemolytic pigment of Group B streptococcus allows bacterial penetration of human placenta. J Exp Med 210: 1265-1281.

34. Sendi P, Johansson L, Dahesh S, Van-Sorge NM, Darenberg J, et al. (2009) Bacterial phenotype variants in group B streptococcal toxic shock syndrome. Emerg Infect Dis 15: 223-232.

35. Lupo A, Ruppen C, Hemphill A, Spellerberg B, Sendi P (2014) Phenotypic and molecular characterization of hyperpigmented group B Streptococci. Int J Med Microbiol 304: 717-724.

36. Almeida A, Villain A, Joubrel C, Touak G, Sauvage E, et al. (2015) Wholegenome comparison uncovers genomic mutations between group b streptococci sampled from infected newborns and their mothers. J Bacteriol 197: 3354-3366. 